\title{
Spatio-temporal variation of spring phenology in Tibetan Plateau and its linkage to climate change from 1982 to 2012
}

\author{
DING Ming-jun1,2 (D http://orcid.org/oooo-ooo2-9623-8886; e-mail: dingmingjun1128@163.com \\ LI Lan-hui ${ }^{1,2}$ (D) http://orcid.org/oooo-0002-5927-6891; e-mail: lilanhui110@163.com \\ NIE Yong4 (D) http://orcid.org/oooo-0oo2-6075-8564; e-mail: nieyong@imde.ac.cn \\ CHEN Qian1 (D)http://orcid.org/oooo-0002-9696-5813; e-mail: ppcastle93@hotmail.com

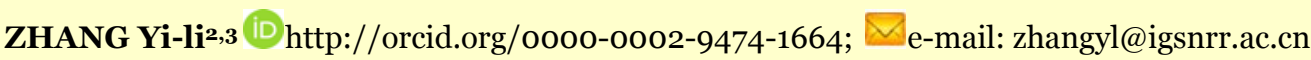 \\ 1 Key Laboratory of Poyang Lake Wetland and Watershed Research, Ministry of Education and School of Geography and \\ Environment, Jiangxi Normal University, Nanchang 330022, China \\ 2 Key Laboratory of Land Surface Pattern and Simulation, Institute of Geographic Sciences and Natural Resources \\ Research, Chinese Academy of Sciences, Beijing 100101, China \\ 3 Center for Excellence in Tibetan Plateau Earth Sciences, Chinese Academy of Sciences, Beijing 10o101, China \\ 4 Institute of Mountain Hazards and Environment, Chinese Academy of Sciences, Chengdu 610o41, China
}

Citation: Ding MJ, Li LH, Nie Y, et al. (2016) Spatio-temporal variation of spring phenology in Tibetan Plateau and its linkage to climate change from 1982 to 2012. Journal of Mountain Science 13(1). DOI: 10.1007/s11629-015-3600-O

(C) Science Press and Institute of Mountain Hazards and Environment, CAS and Springer-Verlag Berlin Heidelberg 2016

\begin{abstract}
The influence of climate change on vegetation phenology is a heated issue in current climate change study. We used GIMMS-3g NDVI data to detect the spatio-temporal dynamics of the start of the growing season (SGS) over the Tibetan Plateau (TP) from 1982 to 2012 and to analyze its relationship with temperature and precipitation. No significant trend was observed in the SGS at the regional scale during the study period $\left(R^{2}=0.03, P=0.352\right)$. However, there were three time periods (1982-1999, 1999-2008 and 2008-2012) with identifiable, distinctly different trends. Regions with a significant advancing trend were mainly scattered throughout the humid and semi-humid areas, whereas the regions with a significant delaying trend were mostly distributed throughout the semi-arid areas. Statistical analysis showed that the response of the SGS to climate change varies spatially. The SGS was significantly correlated with the spring temperature and the start of the thermal growth season (STGS) in the relatively humid area. With increasing aridity, the
\end{abstract}

Received: 22 June 2015

Accepted: 17 September 2015 importance of the spring temperature for the SGS gradually decreased. However, the influences of precipitation and winter temperature on the SGS were complicated across the plateau.

Keywords: Spring phenology; Spatial pattern; Temporal variation; Climate change; Correlation; Tibetan Plateau (TP)

\section{Introduction}

The influence of climate change has become increasingly obvious in a number of social and ecological systems since the 1970s (Rosenzweig et al. 2008). Plant phenology, the timing of recurring biological cycles and their connection to climate, is thought to be one of the most sensitive and valuable biosphere indicators of climate change (Badeck et al. 2004). In recent decades, shifts in the timing of plant growth have been observed worldwide (Parmesan and Yohe 2003; 
Walther 2003; Cook et al. 2012). These shifts may influence the timing of vegetation activity as well as global carbon cycles (Penuelas et al. 2004; Churkina et al. 2005). Furthermore, the changes in plant phenology are of great significance in terms of biodiversity (Both et al. 2006), grain production (Memmott et al. 2007; Meroni et al. 2014) and climate change through biophysical feedback mechanisms (Penuelas et al. 2009; White et al. 2009). Ding et al. (2013) reported that changes in the duration of the growth season will significantly affect animal production in pasture areas.

Changes in vegetation phenology and their links to climate change are poorly understood in some regions with harsh natural conditions. This limits our ability to detect regional vegetation growth (Tang et al. 2009). Over the past couple of decades, the accessibility of information from global remotely sensed data has provided the possibility of studying the patterns and dynamics of global vegetation growth (Zhang et al. 2005; Rembold et al. 2013). Time series data composed of multi-resolution satellite images can objectively detect global-scale changes in vegetative phenology on a uniform timescale and have therefore been used to study phenology patterns relating to climate variability and human actions (Kathuroju et al. 2007; Seghieri et al. 2009; Zhang et al. 2009). Various techniques have been developed to derive vegetation phenology from satellite time series data set (White et al. 2009; Schwartz and Hanes 2010; Hmimina et al. 2013). The Tibetan Plateau (TP) is the highest plateau on earth, and it has a wide range of alpine grasslands, which have a high sensitivity to environmental changes (Piao et al. 2006a, Sun et al. 2012, Deng et al. 2013). Although long-term phenological observation data are lacking for the TP due to its severe physical environment, remotely sensed data, such as timeseries Normalized Difference Vegetation Index (NDVI) data from Global Inventory Modeling and Mapping Studies (GIMMS), SPOT-VEGETATION (SPOT-VGT) and Moderate Resolution Imaging Spectroradiometer (MODIS) are available.

In recent decades, this plateau has experienced substantial warming (Liu and Chen 2000; Ding et al. 2014; Gao et al. 2014), which has resulted in an obvious change in phenology (Yu et al. 2010; Piao et al. 2011; Shen et al. 2011; Song et al. 2011; Ding et al. 2013; Fan et al. 2013). However, there are different views on why the advancing trend in SGS had stalled by the end of the 1990s (Yu et al. 2010, Piao et al. 2011; Shen et al. 2011; Ding et al. 2013; Fan et al. 2013; Shen et al. 2013; Zhang et al. 2013; Zhou et al. 2014). It is well known that climate change may alter vegetation phenology, but both the phenology and the climate controls are spatially heterogeneous (Piao et al. 2011; Shen et al. 2011). Regional differences in the changes in phenology not only reflect on current regional climate signals, but may be enhanced or dampened by different temperature sensitivities across climate regions and vegetation types (Cleland et al. 2006; Sherry et al. 2007). The TP has unique geographical conditions that create a distinct environmental gradient from the southeast to the northwest (Ding et al. 2007; Piao et al. 2004), and this spatial heterogeneity of the environment may lead to a diversity of phenological responses to climate change across the plateau (Ding et al. 2013; Piao et al. 2011; Shen et al. 2011). Thus far, however, there have been very few studies of the spatial pattern of the relationship between the SGS and climatic factors across the entire region, which has severely restricted our understanding of the variations in phenology across the TP within the context of climate change.

The purpose of this study was to detect the spatial and temporal changes in the start of the growing season (SGS) and its linkage to climate factors on the TP from 1982 to 2012 using GIMMS$3 \mathrm{~g}$ NDVI. More specifically, we aimed to answer the following questions: (1) What was the spatial pattern of changes in SGS from 1982 to 2012 in the TP? (2) How did the SGS respond to climate change? (3) Is there a heterogeneous response of SGS to climate change?

\section{Materials and Methods}

\subsection{Study area}

The TP is located in western China (Figure 1). It has an average altitude of approximately $4000 \mathrm{~m}$ above sea level and an area of approximately $2.57 \times$ $10^{6} \mathrm{~km}^{2}$ (Zhang et al. 2002). The temperature is generally higher in the southeast, where altitudes are low, but it is very cold in the northwest, where altitudes are higher. Precipitation mainly occurs in 

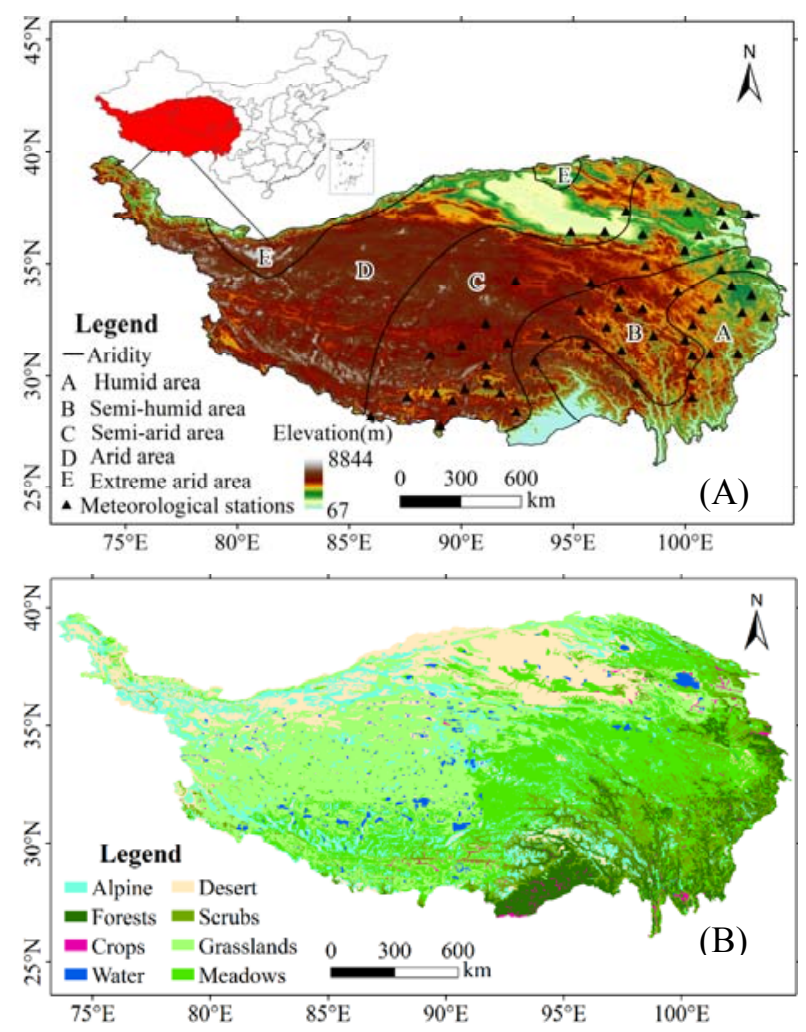

Figure 1 Spatial patterns of (A) aridity and elevation and (B) vegetation types on the Tibetan Plateau. The 57 meteorological stations used in this study are also shown.

the May to September period, and the mean annual precipitation decreases from more than $1000 \mathrm{~mm}$ to $50 \mathrm{~mm}$ from the southeast to the northwest. These patterns of precipitation and temperature result in the aridity increasing from the southeast to the northwest (Figure 1A).

The TP has approximately $1,521,500 \mathrm{~km}^{2}$ of alpine grasslands accounting for $59.15 \%$ of the total area (Ding et al. 2013), which includes alpine meadows, alpine steppes, and alpine deserts. Recent studies have indicated that the grassland ecosystems of the TP play a significant role in the ecological security of China and East Asia (Sun et al. 2012). However, there is an extensive area with sparse or absent vegetation in the cold and dry west. To minimize the impact of bare, sparsely vegetated and evergreen regions, we only used pixels that simultaneously met the following criteria: (1) the average NDVI value in AprilSeptember shall be more than 0.10 ; (2) the maximum annual NDVI value shall exceed 0.15 ; (3) the annual maximum NDVI value occurring between July and September; and (4) the average winter NDVI value shall be less than 0.4 (Shen et al. 2011; Ding et al. 2013).

\subsection{Data set}

NDVI, defined as the ratio of the difference between near-infrared reflectance and red visible reflectance to their sum, is available to compare the seasonal and inter-annual changes in vegetation growth and activity (Myneni et al. 1997; Huete et al. 2002). In this study, we detected the SGS using GIMMS-3g NDVI (1982-2012) and SPOTVGT NDVI (1999-2012) data set.

\subsubsection{NDVI data set from GIMMS-3g}

The GIMMS-3g NDVI data set, the longest time-series NDVI dataset, covering the period from 1981 (July) to 2012, were obtained from the Advanced Very High Resolution Radiometer instrument onboard the National Oceanic and Atmospheric Administration (NOAA) satellite series. The GIMMS-3g NDVI products, with a spatial resolution of $8 \mathrm{~km}$, were compiled by merging segments (data strips) of half-month periods using the Maximum Value Composition (MVC) method (Holben 1986). These data had been calibrated for sensor shifts and corrected to remove the effects of sensor degradation, satellite orbital drift, solar zenith angles and volcanic aerosols.

\subsubsection{NDVI data set from SPOT-VGT}

The SPOT-VGT NDVI data set, covering the period from 1998 (April) to 2012 with a spatial resolution of $1 \mathrm{~km}$, was derived from the vegetation instrument of the Système Pour l'Observation de la Terre (SPOT). It was compiled by merging 10-day segments (data strips) using the MVC method to minimize non-vegetation effects. The data had been preprocessed by the Vegetation Processing Centre at the Flemish Institute for Technological Research in Belgium (Maisongrande et al. 2004). A series of processes, including atmospheric correction, radiometric correction and geometric correction, were performed to ensure the quality of the data. The purpose of using this data set here is to validate the results derived from the GIMMS-3g.

\subsubsection{Meteorological data}

To investigate the relationship between the SGS and climate, we obtained daily meteorological 
data from 57 meteorological stations distributed across the TP (Figure 1A) and operated by the State Meteorological Administration of China (http:// cdc.nmic.cn). These data, which spanned the 1982 to 2012 period, included the daily mean temperature $\left(T_{\text {mean }}\right)$, daytime temperature $\left(T_{\max }\right)$, nighttime temperature $\left(T_{\min }\right)$ and precipitation.

\subsubsection{Preprocessing of NDVI data}

Despite all of the efforts to improve the data quality, there were spurious changes in vegetation indices resulting from inevitable atmospheric contamination in the data set (Chen et al. 2004) which may affect the detection of the vegetation SGS. For the purpose of reducing contamination by clouds, snow and ice, the Savitzky-Golay (S-G) filtering technique was applied to each annual NDVI curve (Chen et al. 2004). As a result of this filtering procedure, two types of data were obtained: one consisted of smoothed data with the same temporal resolution as the raw data, while the other was smoothed data with a temporal resolution of 1 day.

\subsection{Climatological variables}

There is currently no universal method to define the start of the thermal growing season (STGS) (Linderholm 2006). Robeson (2002) described the STGS as the date of the last spring freeze (i.e., a daily minimum temperature of $<0^{\circ} \mathrm{C}$ ). Other workers have defined the STGS based on temperature thresholds in a predefined number of days (Linderholm et al. 2008, Walther and Linderholm 2006). In this study, we used the definition of the STGS reported by Linderholm et al. (2008) and Dong et al. (2012). Namely, STGS is

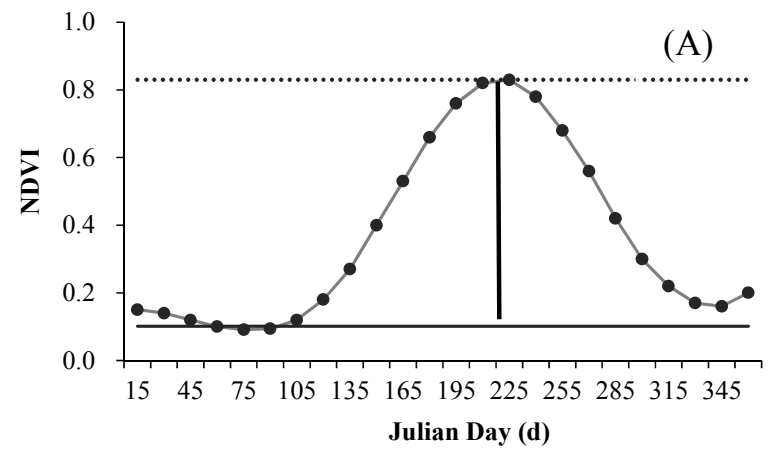

defined as the last day of the first 6-day period with a daily mean temperature greater than $5^{\circ} \mathrm{C}$ after the last spring frost (daily mean temperature $<0^{\circ} \mathrm{C}$ ).

To investigate the response of the SGS to the change in climate, we performed partialcorrelation analyses between SGS and climate variables over the last 31 years. Sensitivity analyses were conducted to evaluate the effects of temperature and precipitation in different lengths of the pre-season period (15, 30 and 60 days) on spring phenology. All of the pre-season periods were specified to end on the same date, which was calculated by averaging the SGS over the all years. We then computed the mean temperature and cumulative precipitation of each pre-season period preceding this date for each year.

\subsection{Detection of vegetation SGS from satellite images}

Many methods have been developed to retrieve phenology from seasonal NDVI data (White et al. 2009; Cong et al. 2012). The most widely used methods include: the threshold of maximum relative change, used by Piao et al. (2006b, 2011) and Ding et al. (2013); the threshold of maximum relative change ratio, used by Zhang et al. (2013); the threshold of NDVI ratio, used by White et al. (1997) and Yu et al. (2010); and the maximum change in curvature, used by Zhang et al. (2003). However, a universally accepted method does not exist. In this study, we applied a threshold for the NDVI ratio, developed by White et al. (1997) to derive the SGS. We first found the maximum and minimum NDVI values based on the smoothed data with the same temporal resolution as the raw data (Figure 2A). Yu et al. (2010) evaluated the

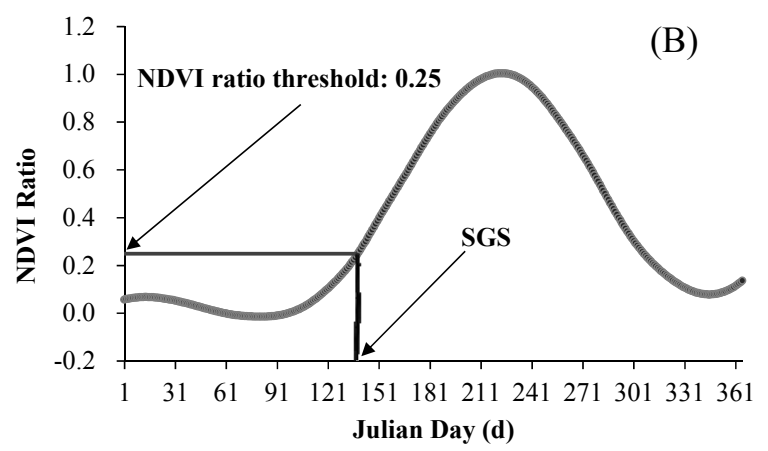

Figure 2 Normalized difference vegetation index (NDVI) ratio method used to derive the start of the growing season (SGS)(A). The SGS is assumed to occur when the SGS-specific threshold is exceeded (B). 
average NDVI curve over 24 years (GIMMS) and noted that the NDVI reached its minimum value in February and March. To eliminate the influence of snow cover, the annual NDVI minimum was replaced by the average NDVI in these two months. Then, based on the smoothed data with a resolution of 1 day, we calculated the NDVI ratio using the following formula.

$\mathrm{NDVI}_{\text {ratio }}=\left(\mathrm{NDVI}_{(\mathrm{t})}-\mathrm{NDVI}_{\text {min }}\right) /\left(\mathrm{NDVI}_{\text {max }}-\mathrm{NDVI}_{\text {min }}\right)$ (1)

Where $t$ is the time. The appropriate threshold was determined using ground observation data from 18 grassland-monitoring stations. The final thresholds were selected by considering two indicators, the mean absolute error (MAE) and the root-meansquare error (RMSE), which were calculated between the ground observations and the modeled SGS. Finally, we selected an NDVI ratio threshold of 0.25 (MAE $=10.66 \mathrm{~d}$ and $\mathrm{RMSE}=13.41 \mathrm{~d}$ ) for the SGS (Figure 2B).

\section{Results and Discussion}

\subsection{Change in SGS at the regional scale}

Figure 3 illustrates the inter-annual variation of the vegetation SGS from 1982 to 2012. No statistically significant trend could be found for the vegetation SGS over the entire study period $\left(R^{2}=\right.$ 0.03, $P=0.352$ ), although three distinctly different trends in the 1982-1999, 1999-2008 and 20082012 periods were identified. The SGS advanced by 0.20 days year ${ }^{-1}$ from 1982 to $1999\left(R^{2}=0.15, P=\right.$ 0.109). There was then a short delaying trend after 1998, which resulted in the SGS advancing more significantly $\left(R^{2}=0.72, P=0.02\right)$ from 1999 to

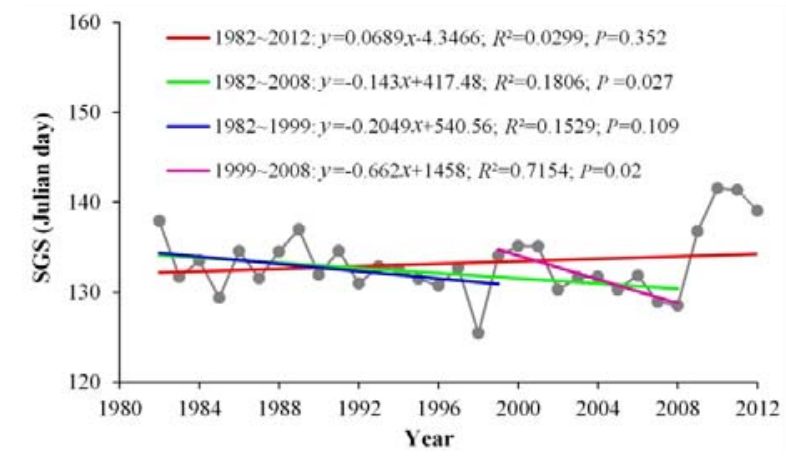

Figure 3 Inter-annual variation in start of the growing season (SGS) of the vegetation for the entire study area from 1982 to 2012, derived from GIMMS-3g NDVI data.
2008 than in the 1982-1999 period. The SGS advanced significantly by 0.14 days year $^{-1}$ from 1982 to $2008\left(R^{2}=0.18, P=0.027\right)$, but the trend toward an earlier SGS then reversed after 2008, when there was an abrupt delaying trend.

The accuracy of the SGS results obtained in this study could be assessed through a comparison with the findings of previous studies. At the regional scale, the trend in the annual changes in the SGS for the 1982-1998 periods is in agreement with the results of $\mathrm{Yu}$ et al. (2010) and Piao et al. (2011), who used GIMMS (1982-2006). Similarly, the trend for the $1999-2008$ periods is in accordance with the findings of Ding et al. (2013) and Shen et al. (2011), who used SPOT-VGT NDVI. However, the trend is different from the results of Song et al. (2011) and Zhang et al. (2013) who used MODIS and GIMMS-3g, respectively, especially for the period after 2008. Zhang et al. (2013) suggested that the GIMMS NDVI data may have severe data-quality issues in most parts of the western plateau. By merging GIMMS-based SGS data from 1982 to 2000 with the SGS based on SPOT-VGT data from 2001 to 2011, they found that the alpine vegetation SGS experienced a continuous advancing trend from 1982 to 2011. Ding et al. (2015) also suggested that it is important to pay attention to the types of vegetation with high or low coverage when studying vegetation phenology in the TP using remote sensing techniques.

In the present study, we compared the consistency of the SGS values derived from GIMMS-3g and SPOT-VGT data (Figure 4) and found a correlation coefficient of $0.46(P=0.099)$ between the GIMMS-3g and SPOT-VGT data for 1999-2012. The SGS values derived from SPOT

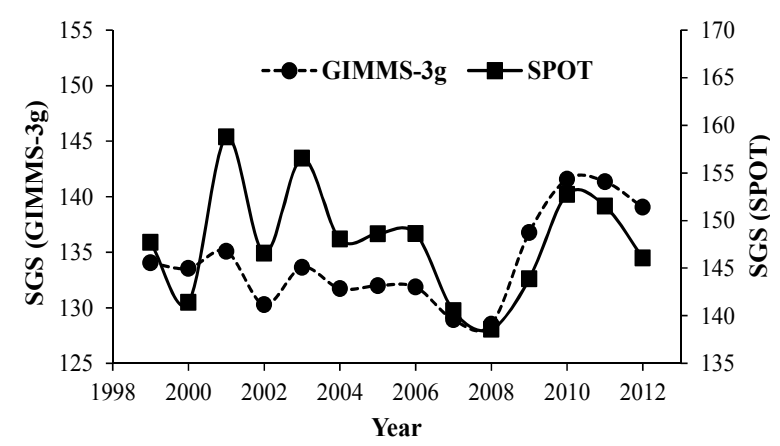

Figure 4 Comparison of inter-annual variation in start of the growing season (SGS) derived from SPOT and GIMMS-3g data sets from 1999 to 2012. 
and GIMMS show the same sudden delaying trend after 2008. Furthermore, the results of a few previous studies found the same phenomenon. Fu et al. (2014) compared the inter-annual variability of the SGS values from MODIS products and four phenology models and found the SGS values for grassland also showed a delaying trend from 2008 to 2010 over the northern hemisphere. To account for the potential uncertainty in different phenology models based on remote sensing, Cong et al. (2013) conducted a multi-method investigation to quantify changes in the SGS from 1982 to 2010 over the temperature zones of China and also found that the SGS derived from most of the methods showed a delaying trend after 2008. The studies listed here all agree with the results of this study.

\subsection{Spatial patterns of trends in the SGS}

Figure 5 shows the spatial patterns in the trends of the SGS. There was a strong spatial heterogeneity throughout the plateau for the trend in SGS. During the entire study period (Figure $5 \mathrm{~A}$ and Table 1), the number of pixels for which the delaying trend was significant $(P<0.1)$ corresponds to approximately $23.39 \%$ of the total number of pixels; these pixels were mainly distributed throughout the semi-arid areas. The regions with a significant advancing trend account for approximately $9.51 \%$ of the total, and they were scattered mainly throughout the humid and semihumid areas. During the 1982-1999 period (Figure $5^{\mathrm{B}}$ and Table 1), the pixels with a significant advancing trend account for $17.72 \%$ of the total, and they were mainly distributed throughout the humid and semi-humid areas; these pixels were six times more numerous than those showing a significant delaying trend. There was a clear advancing trend throughout the entire plateau for the 1999-2008 period. As shown in Figure ${ }_{5} \mathrm{C}$ and Table 2, the proportion of significant advancing pixels was $22.30 \%$; these were mainly distributed in semi-humid and semi-arid areas and were 22 times more abundant than the pixels with a significant delaying trend. In general, for the 19822008 periods, the SGS values mostly show an advancing trend (Figure $5 \mathrm{D}$ ). Based on the trend significance test $(P<0.1)$, approximately $27.66 \%$ of the pixels showed an advancing trend, which is much higher than the proportion of pixels with a
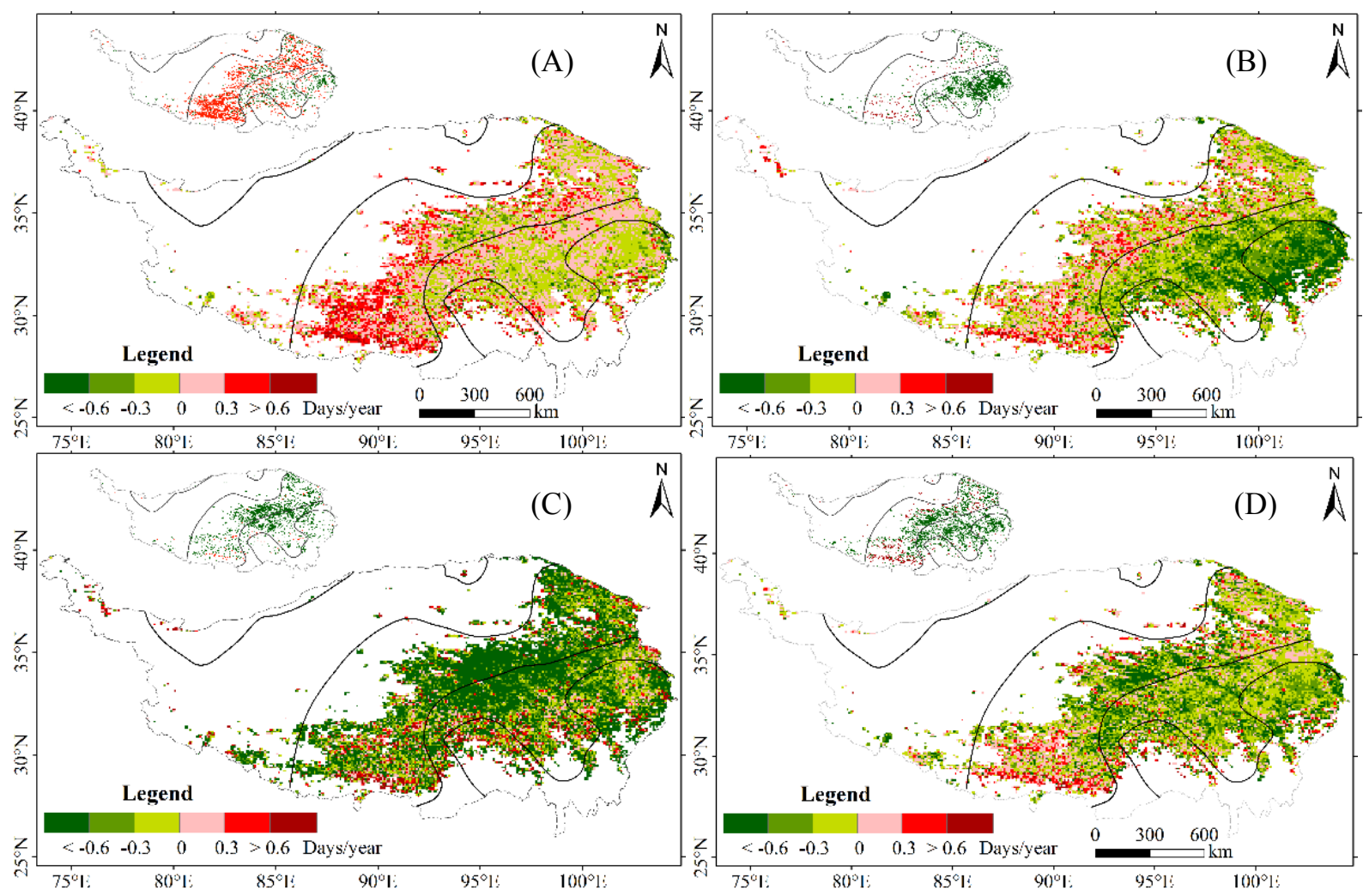

Figure 5 Spatial pattern of trends in the start of the growing season (SGS) values in the Tibetan Plateau. (A) 19822012; (B) 1982-1999; (C) 1999-2008; and (D) 1982-2008.The small map on top illustrates significant pixels $(P<0.1)$. 
delaying trend (Table 2). The delaying trend of the entire study period is related to the larger delaying trend after 2008.

\subsection{Correlation between SGS and climate factors}

\subsubsection{Temperature}

\section{thresholds for SGS}

The relationship between temperature or cumulative temperature at the date of the SGS and the mean temperature across all 57 meteorological stations (Figure 6) indicates that the temperature threshold of the SGS is significantly and positively correlated with the mean annual temperature $\left(R^{2}\right.$ $=0.65, P<0.001)$ and that the cumulative temperature threshold is also significantly and positively correlated with the mean annual temperature $\left(R^{2}=0.81, P<\right.$ 0.001). These results indicate that, in contrast to the vegetation in warmer areas, vegetation in colder environments demanded a lower threshold temperature for green-up (Jin et al. 2013). Extrapolating space for time, we can infer that, in

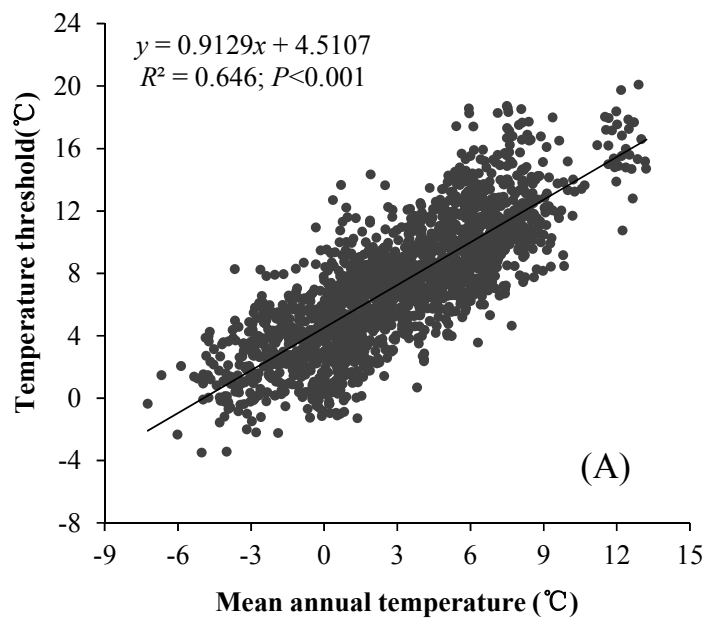

Table 1 Percentage of pixels with advancing or delaying trends of the start of the growing season (SGS)

\begin{tabular}{|l|l|l|l|l|}
\hline $\begin{array}{l}\text { Pixels with advancing } \\
\text { trend (\%) }\end{array}$ & $1982-1999$ & $1999-2008$ & $1982-2008$ & $1982-2012$ \\
\hline $\begin{array}{l}\text { Pixels with significant } \\
\text { advancing trend (\%) }\end{array}$ & 17.72 & 80.78 & 71.77 & 39.09 \\
\hline $\begin{array}{l}\text { Pixels with delaying } \\
\text { trend (\%) }\end{array}$ & 32.32 & 19.22 & 28.23 & 6.52 \\
\hline $\begin{array}{l}\text { Pixels with significant } \\
\text { delaying trend (\%) }\end{array}$ & 2.76 & 1.11 & 5.33 & 23.4
\end{tabular}

Table 2 Correlation between the start of the growing season (SGS) and winter and spring temperatures and precipitation for the meteorological stations

\begin{tabular}{|c|c|c|c|c|}
\hline \multirow[b]{2}{*}{ Study area } & \multirow[b]{2}{*}{ Period } & \multicolumn{3}{|c|}{$R$ (SGS) } \\
\hline & & Apr-May $\left(M T_{\text {mean }}\right)$ & Apr-May（SP） & $\begin{array}{l}\text { Winter } \\
\left(M T_{\text {mean }}\right)\end{array}$ \\
\hline \multirow{4}{*}{ Humid } & $1982-1999$ & $-0.65^{* * *}$ & -0.08 & -0.17 \\
\hline & $1982-2008$ & $-0.62^{* * *}$ & -0.02 & -0.14 \\
\hline & 1999-2008 & -0.55 & 0.27 & -0.05 \\
\hline & $1982-2012$ & $-0.36^{* *}$ & 0.09 & -0.05 \\
\hline \multirow{4}{*}{ Semi-humid } & $1982-1999$ & $-0.48^{* *}$ & 0.04 & 0.17 \\
\hline & $1982-2008$ & $-0.57^{* * *}$ & 0.06 & 0.02 \\
\hline & 1999-2008 & -0.50 & $0.57^{*}$ & 0.13 \\
\hline & $1982-2012$ & -0.23 & 0.19 & 0.18 \\
\hline \multirow{4}{*}{ Semi-arid } & $1982-1999$ & -0.18 & 0.25 & -0.03 \\
\hline & $1982-2008$ & $-0.37^{*}$ & 0.03 & -0.25 \\
\hline & $1999-2008$ & -0.26 & 0.00 & -0.11 \\
\hline & $1982-2012$ & 0.09 & 0.18 & 0.14 \\
\hline
\end{tabular}

Notes: $M T_{\text {mean }}$ : mean of daily mean temperature; $S P$ : sum of precipitation; ${ }^{* * *}$ : $P<0.01{ }^{* *}: P<0.05 ;^{*}: P<0.1$.

the context of future global warming, the vegetation SGS may require a higher threshold temperature (Piao et al. 2011). Such an increase in the SGS threshold in response to a rising mean annual temperature may be attributed to the acclimation of vegetation to higher temperatures

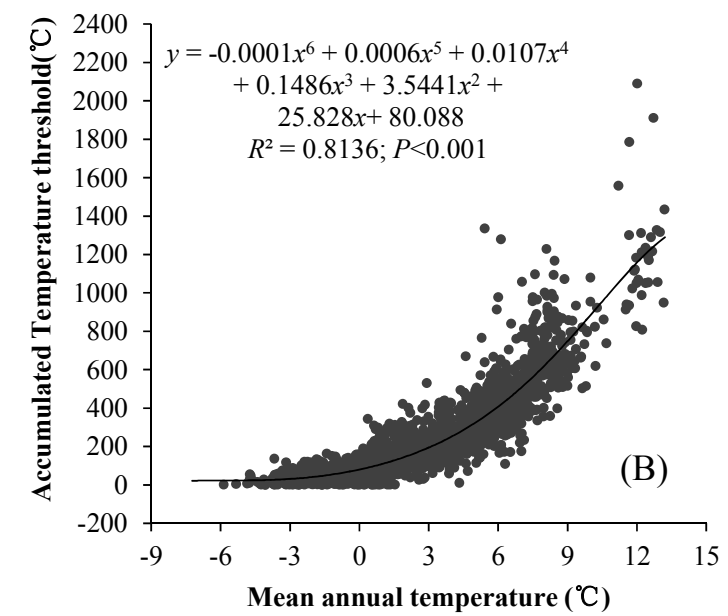

Figure 6 Relationship between temperature threshold of start of the growing season (SGS) and mean annual temperature across meteorological stations in the Tibetan Plateau. (A) Temperature threshold and (B) accumulated temperature threshold. 
(White et al. 1999, Piao et al. 2011). The observed dependence of the SGS on the mean annual temperature suggests that a $1^{\circ} \mathrm{C}$ increase in the mean annual temperature of the TP would increase the temperature threshold of the vegetation SGS by $0.86^{\circ} \mathrm{C}$; this is in agreement with the results of Piao et al. (2011) and Jin et al. (2013). The conclusions above, however, are merely inferred from remote sensing data alone; additional research is required to determine whether these results indicate that an increased temperature was required for the SGS at a given location or cumulative temperature with the global climate warming (Shen et al. 2011).

\subsubsection{Correlation between SGS and STGS}

Figure 7 shows the relationship between the SGS and the STGS. Across the entire study area, the STGS is significantly and positively correlated with the SGS from 1982 to $2008\left(R^{2}=0.258, P=\right.$ 0.007 ), although there was a spatial heterogeneity throughout the plateau between the different regions. For the humid area, the STGS is significantly and positively correlated with the SGS from 1982 to $2008\left(R^{2}=0.40, P<0.001\right)$. However, in the semi-humid and semi-arid areas, although the STGS was also significantly and positively correlated with the SGS from 1982 to
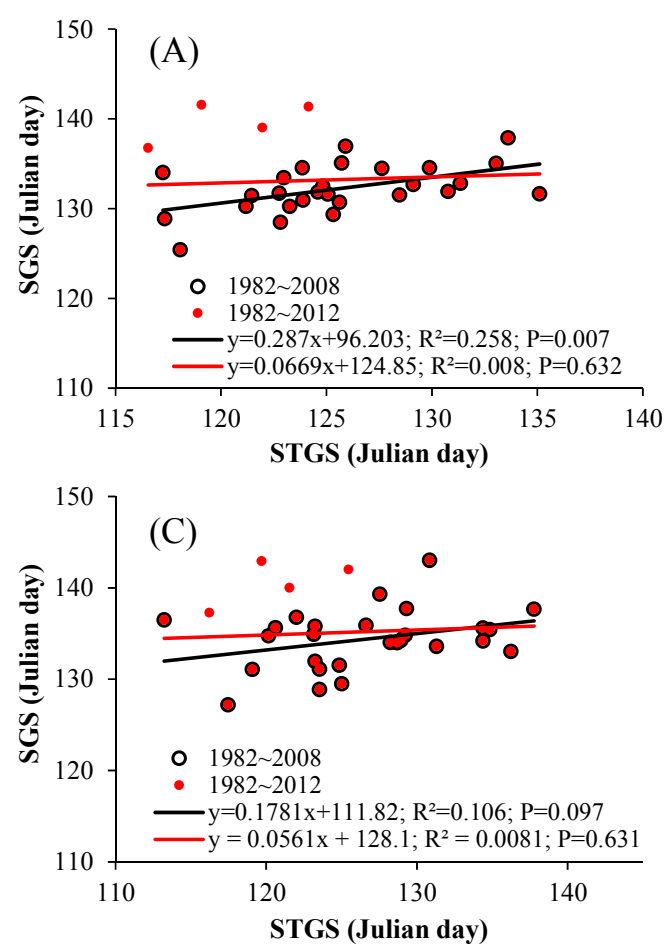

2008, the significance levels are lower than those of the humid areas. These results indicate that the change in spring temperature has an important effect on on the SGS in the TP, although the significance is different in different areas. In the semi-humid and semi-arid areas, the importance of temperature is lower than that in the humid areas. As a result of the abrupt delay after 2008, the STGS had no significant correlation with the vegetation SGS over the whole study period.

\subsubsection{Correlation between SGS and temperature and precipitation}

Previous research using GIMMS NDVI data sets has shown a prominent reversal of the SGS on the TP at the end of the 1990s, with a significant trend of an advancing SGS from 1982 to 1998 and a trend of a delayed SGS from 1998 to 2006 (Yu et al. 2010; Piao et al. 2011; Ding et al. 2013). The reported causes for the delay in SGS on the TP are diverse and include opposite spring temperature trends in the two periods (Piao et al. 2011) and winter warming resulting in a failure to sufficiently chill the plants in the winter (Yu et al. 2010). In the present study, we extended the time series to 2012 and found that the response of SGS to spring temperature is more sensitive than the response to
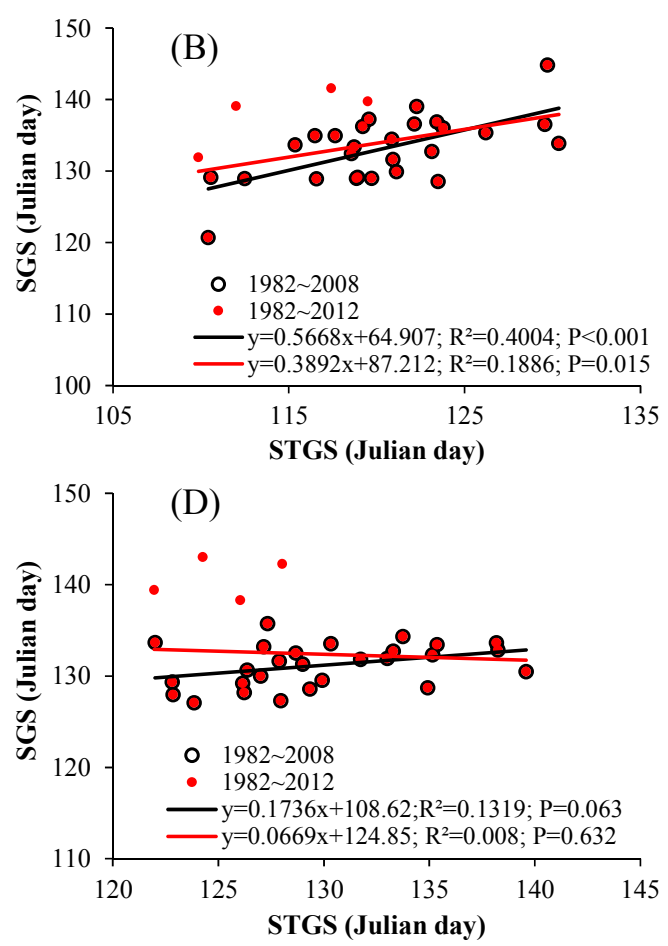

Figure 7 Relationship between the start of the growing season (SGS) and thermal growth season (STGS) across meteorological stations (A) over the whole study area, (B) in the humid areas, (C) in the semi-humid areas, and (D) in the semi-arid area. 
the cumulative spring precipitation and winter temperature. However, there was a spatial heterogeneity for this response. With increasing aridity, the intensity of the influence of temperature on the SGS gradually decreases (Table 2).

Based on the GIMMS-NDVI data sets from 1982 to 2006, Shen et al. (2011) concluded that in relatively moist areas, the SGS tended to be advanced by the increasing pre-season temperature. Cong et al. (2013) found that with the increase in cumulative pre-season precipitation, the responses of spring phenology to temperature became intense across the northern part of China. They also found that when the length of the pre-season period was $>120$ days, there was a significant reduction in the number of stations with a negative correlation between spring phenology and temperature. In this study, we also found that the temperature was a key climatic factor influencing the SGS in the relatively moist areas. However, with increasing aridity, the importance of temperature was gradually reduced. As the length of the pre-season period was extended, the importance of temperature first increased and then decreased. The relationship between the SGS and the $M T_{\text {mean }}$ for the $30 \mathrm{~d}$ period before SGS is the strongest (Table 3).

Piao et al. (2015) found the vegetation greenup in spring is triggered more by the daytime temperature $\left(T_{\max }\right)$ than by the nighttime temperature $\left(T_{\min }\right)$. In our study, we also found the correlation between the SGS and $T_{\max }$ is better than that between SGS and $T_{\min }$. However, there was a spatial heterogeneity for the correlation. With increasing aridity, the intensity of the influence of temperature on the SGS gradually decreases. As the length of the pre-season period was extended, the importance of temperature first increased and then decreased. The relationship between the SGS and the $M T_{\max }$ for the $30 \mathrm{~d}$ period before SGS is the

Table 3 Correlation between the start of the growing season (SGS) and mean temperature and cumulative precipitation before the SGS

\begin{tabular}{|c|c|c|c|c|c|c|c|}
\hline \multirow{2}{*}{ Study area } & \multirow{2}{*}{ Period } & \multicolumn{3}{|c|}{$M T_{\text {mean }}$ for x days before SGS } & \multicolumn{3}{|c|}{$S P$ for x days before SGS } \\
\hline & & $15 \mathrm{~d}$ & $30 \mathrm{~d}$ & $60 \mathrm{~d}$ & $15 \mathrm{~d}$ & $30 \mathrm{~d}$ & $60 \mathrm{~d}$ \\
\hline \multirow{4}{*}{ Humid } & 1982-1999 & $-0.75^{* * *}$ & $-0.76^{* * *}$ & $-0.58^{* *}$ & -0.17 & 0.38 & 0.31 \\
\hline & $1982-2008$ & $-0.71^{* * *}$ & $-0.68^{* * *}$ & $-0.49^{* *}$ & -0.12 & 0.29 & 0.22 \\
\hline & $1999-2008$ & -0.43 & -0.34 & -0.27 & -0.03 & 0.24 & 0.25 \\
\hline & $1982-2012$ & $-0.44^{* *}$ & $-0.50^{* * *}$ & $-0.43^{* *}$ & -0.15 & 0.26 & $0.38^{*}$ \\
\hline \multirow{4}{*}{ Semi-humid } & 1982-1999 & $-0.51^{* *}$ & $-0.60^{* * *}$ & -0.35 & -0.24 & 0.09 & 0.11 \\
\hline & 1982-2008 & $-0.52^{* * *}$ & $-0.62^{* * *}$ & $-0.45^{* *}$ & -0.32 & -0.04 & -0.04 \\
\hline & $1999-2008$ & $-0.64^{*}$ & -0.29 & -0.42 & -0.03 & 0.05 & -0.22 \\
\hline & $1982-2012$ & -0.10 & -0.25 & -0.17 & -0.23 & 0.03 & 0.14 \\
\hline \multirow{4}{*}{ Semi-arid } & $1982-1999$ & -0.10 & -0.13 & 0.05 & -0.07 & -0.06 & -0.05 \\
\hline & $1982-2008$ & -0.24 & -0.30 & -0.28 & -0.25 & -0.20 & -0.22 \\
\hline & $1999-2008$ & -0.49 & -0.39 & -0.51 & $-0.59^{*}$ & -0.52 & $-0.64^{*}$ \\
\hline & $1982-2012$ & 0.15 & 0.15 & 0.16 & 0.15 & 0.18 & -0.03 \\
\hline
\end{tabular}

Notes: $M T_{\text {mean }}$ : mean of daily mean temperature; $S P$ : sum of precipitation; ${ }^{* * *}: P<0.01$; $^{* *}: P<0.05$; $^{*} P<0.1$.

Table 4 Correlation between the start of the growing season (SGS) and mean daytime temperature ( $\left.T_{\max }\right)$ and nighttime temperature ( $\left.T_{\mathrm{min}}\right)$ prior to the SGS

\begin{tabular}{|c|c|c|c|c|c|c|c|}
\hline \multirow{2}{*}{ Study area } & \multirow{2}{*}{ Periods } & \multicolumn{3}{|c|}{$M T_{\max }$ for x days before SGS } & \multicolumn{3}{|c|}{$M T_{\min }$ for x days before SGS } \\
\hline & & $15 \mathrm{~d}$ & $30 \mathrm{~d}$ & $60 \mathrm{~d}$ & $15 \mathrm{~d}$ & $30 \mathrm{~d}$ & $60 \mathrm{~d}$ \\
\hline \multirow{4}{*}{ Humid } & 1982-1999 & $-0.76^{* * *}$ & $-0.78^{* * *}$ & $-0.53^{* *}$ & $-0.66 * * *$ & $-0.66^{* * *}$ & $-0.58^{* *}$ \\
\hline & $1982-2008$ & $-0.76^{* * *}$ & $-0.72^{* * *}$ & $-0.47^{* *}$ & $-0.59^{* * *}$ & $-0.58^{* * *}$ & $-0.51^{* * *}$ \\
\hline & 1999-2008 & $-0.75^{* *}$ & -0.41 & -0.32 & -0.05 & -0.23 & -0.24 \\
\hline & $1982-2012$ & $-0.49^{* * *}$ & $-0.55^{* * *}$ & $-0.39^{* *}$ & $-0.31^{*}$ & $-0.39^{* *}$ & $-0.47^{* *}$ \\
\hline \multirow{4}{*}{ Semi-humid } & $1982-1999$ & -0.40 & $-0.52^{* *}$ & -0.38 & -0.03 & -0.22 & -0.12 \\
\hline & $1982-2008$ & $-0.39^{* *}$ & $-0.50^{* * *}$ & $-0.38^{*}$ & -0.09 & -0.30 & -0.23 \\
\hline & 1999-2008 & -0.58 & -0.06 & -0.18 & $-0.77^{* *}$ & -0.44 & -0.53 \\
\hline & $1982-2012$ & -0.12 & -0.26 & -0.17 & -0.08 & -0.07 & -0.08 \\
\hline \multirow{4}{*}{ Semi-arid } & 1982-1999 & -0.20 & -0.11 & -0.15 & 0.03 & -0.03 & 0.01 \\
\hline & $1982-2008$ & -0.15 & -0.27 & $-0.42^{* *}$ & -0.09 & -0.24 & $-0.35^{*}$ \\
\hline & $1999-2008$ & -0.36 & -0.31 & -0.46 & -0.34 & $-0.63^{*}$ & $-0.72^{* *}$ \\
\hline & $1982-2012$ & -0.21 & 0.14 & 0.08 & 0.23 & 0.27 & 0.20 \\
\hline
\end{tabular}

Notes: $M T_{\min }$ : mean of nighttime temperature $\left(T_{\min }\right) ; M T_{\max }$ : mean of daytime temperature $\left(T_{\max }\right) ;{ }^{* *}: P<0.01 ;{ }^{* *}$ : $P<0.05$; ${ }^{*} P<0.1$. 
strongest (Table 4).

In our study, we found that the response of SGS to spring temperature is more sensitive than the response to winter temperature and precipitation. However, there was a spatial heterogeneity for the response. With the increase in aridity, the intensity of the influence of temperature on the SGS gradually decreases. The results are particularly obvious in the 1982-2008 period. Thus, we can explain that the variation in the SGS is driven by spring temperature change. To a certain degree, we also thought that the sudden delay of SGS after 2008 was caused by the spring temperature, which showed a decreasing trend after 2008 (Figure 8). Tao et al. (2013) also found an opposite trend in the annual average temperature in Qinghai and Xizang Province, which was obvious in daytime. However, the consistency between the SGS and spring temperature was not perfect because spring temperature influenced the SGS in relatively humid areas. This indicated that there were many factors beyond spring temperature which drive the SGS.

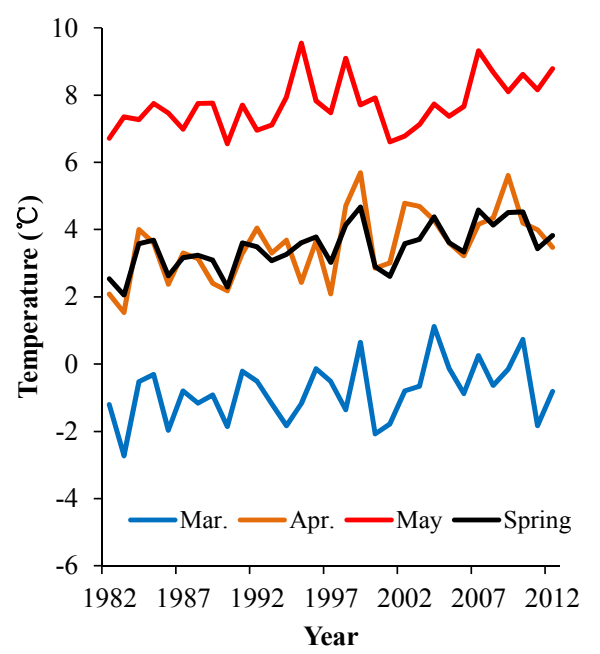

Figure 8 Inter-annual variation in spring temperature for the entire study area from 1982 to 2012.

\section{Conclusions}

Using the GIMMS-3g NDVI data set and concurrent meteorological records from 1982 to 2012, we explored the spatio-temporal changes in the SGS and characterized their relationship to temperature and precipitation on the TP. At the regional scale, no significant trend in the SGS was observed over the entire study period $\left(R^{2}=0.03, P=\right.$ 0.352). Three distinctly different trends in the 1982-
1999, 1999-2008 and 2008-2012 periods were identified. From 1982 to 1999, the SGS advanced significantly, by 0.20 days year ${ }^{-1}\left(R^{2}=0.15, P=\right.$ 0.109). However, there was a short delaying trend after 1998, which resulted in the SGS advancing more significantly from 1999 to $2008\left(R^{2}=0.72, P=\right.$ o.02) than in the 1982-1999period. However, the trend toward an earlier SGS appeared to be reversed after 2008, when there was an abrupt delaying trend. With respect to the spatial pattern, the pixels for the delaying trend were mainly distributed throughout the semi-arid areas. The regions with a significant advancing trend were scattered mainly within the humid and semi-humid areas. For the 1982-2008 period, based on the trend significance test $(P<0.1)$, approximately $27.66 \%$ of the pixels showed an advancing trend, which was much higher than the proportion of pixels with a delaying trend. For the whole study area, a delaying trend was seen after 2008.

The temperature and cumulative temperature thresholds of the SGS were significantly and positively correlated with the mean annual temperature, which means that the vegetation SGS may require an increasing temperature threshold with global warming. Such an increase in the SGS threshold in response to an increasing mean annual temperature may be attributed to growth acclimation of vegetation to higher temperatures. Statistical analysis shows that the SGS is significantly correlated with the spring temperature and STGS in the relatively humid area. That is, the SGS is advanced with increasing spring temperatures and the advancement of the STGS. However, there is no relationship between the SGS and the winter temperature. The response of the SGS to climate change varies spatially, and we found that the importance of the spring temperature for the SGS gradually decreased with increasing aridity.

\section{Acknowledgments}

This study was supported by the Strategic Priority Research Program of the Chinese Academy of Sciences (Grant No. XDB03030500); National Natural Science Foundation of China (Grant Nos. 41201095, 41171080, 41371120). The authors would like to thank the reviewers for their invaluable suggestions. 


\section{References}

Badeck FW, Bondeau A, Bottcher K, et al. (2004) Responses of spring phenology to climate change. New Phytologist 162(2): 295-309. DOI: 10.1111/j.1469-8137.2004.01059.x

Both C, Bouwhuis S, Lessells CM, et al. (2006) Climate change and population declines in a long-distance migratory bird. Nature 441(7089): 81-83. DOI: $10.1038 /$ natureo4539

Chen J, Jonsson P, Tamura M, et al. (2004) A simple method for reconstructing a high-quality NDVI time-series data set based on the Savitzky-Golay filter. Remote Sensing of Environment 91(3-4): 332-344. DOI: 10.1016/j.rse.2004.03. 014

Churkina G, Schimel D, Braswell BH, et al. (2005) Spatial analysis of growing season length control over net ecosystem exchange. Global Change Biology 11(10): 1777-1787. DOI: 10.1111/j.1365-2486.2005.001012.x

Cleland EE, Chiariello NR, Loarie SR, et al. (2006) Diverse responses of phenology to global changes in a grassland ecosystem. Proceedings of the National Academy of Sciences of the United States of America 103(37): 13740-13744. DOI:10.1073/pnas.0600815103

Cong N, Piao SL, Chen AP, et al. (2012) Spring vegetation greenup date in China inferred from SPOT NDVI data: A multiple model analysis. Agricultural and Forest Meteorology 165: 104113. DOI:10.1016/j.agrformet.2012.06.009

Cong N, Wang T, Nan HJ, et al. (2013) Changes in satellitederived spring vegetation green-up date and its linkage to climate in China from 1982 to 2010: a multimethod analysis. Glob Chang Biol 19(3): 881-891. DOI:10.1111/gcb.12077

Cook BI, Wolkovich EM, Parmesan C (2012) Divergent responses to spring and winter warming drive community level flowering trends. Proceedings of the National Academy of Sciences of the United States of America 109(23): 90009005. DOI:10.1073/pnas.1118364109

Deng SF, Yang TB, Zeng B, et al. (2013)Vegetation cover variation in the Qilian Mountains and its response to climate change in 2000-2011. Journal of Mountain Science 10(6): 1050-1062. DOI: $10.1007 / \mathrm{s} 11629-013-2558-\mathrm{Z}$

Ding MJ, Li LH, Zhang YL, et al. (2014) Temperature Change and Its Elevation Dependency on the Tibetan Plateau and Its Vicinity from 1971 to 2012. Resources Science 36(7): 15091518. (In Chinese)

Ding MJ, Li LH, Zhang YL, et al. (2015) Start of vegetation growing season on the Tibetan Plateau inferred from multiple methods based on GIMMS and SPOT NDVI data. Journal of Geographical Sciences 25(2): 131-148. DOI:10.1007/s11442015-1158-y

Ding MJ, Zhang YL, Sun XM, et al. (2013) Spatiotemporal variation in alpine grassland phenology in the QinghaiTibetan Plateau from 1999 to 2009. Chinese Science Bulletin 58(3): 396-405. DOI: 10.1007/s11434-012-5407-5

Dong MY, Jiang Y, Zheng C, et al. (2012) Trends in the thermal growing season throughout the Tibetan Plateau during 19602009. Agricultural and Forest Meteorology 166: 201-206. DOI: 10.1016/j.agrformet.2012.07.013

Fan J, Huang J, Zhang M (2013) Retrieval of Cropping Index in China Using Time Series of SPOT Vegetation NDVI. Sensor Letters 11(6): 1134-1140. DOI: 10.1166/sl.2013.2892

Fu Y, Zhang H, Dong W, et al. (2014) Comparison of Phenology Models for Predicting the Onset of Growing Season over the Northern Hemisphere. PlOS ONE 9(10): e109544. DOI: 10.1371/journal.pone.0109544

Gao L, Hao L, Chen XW (2014) Evaluation of ERA-interim monthly temperature data over the Tibetan Plateau. Journal of Mountain Science 11(5): 1154-1168. DOI: $10.1007 / \mathrm{s} 11629-$ 014-3013-5

Hmimina G, Dufrêne E, Pontailler JY, et al. (2013) Evaluation of the potential of MODIS satellite data to predict vegetation phenology in different biomes: An investigation using ground-based NDVI measurements. Remote Sensing of Environment 132: 145-158. DOI: 10.1016/j.rse.2013.01.010

Holben BN (1986) Characteristics of maximum-value composite images from temporal AVHRR data. International Journal of Remote Sensing 7(11): 1417-1434. DOI: 10.1080/ 01431168608948945

Huete A, Didan K, Miura T, et al. (2002) Overview of the radiometric and biophysical performance of the MODIS vegetation indices. Remote Sensing of Environment 83(1-2): 195-213. DOI: 10.1016/soo34-4257(02)ooo96-2

Jin, ZN,Zhuang QL, He JS, et al. (2013) Phenology shift from 1989 to 2008 on the Tibetan Plateau: an analysis with a process-based s-oil physical model and remote sensing data. Climatic Change 119(2): 435-449. DOI: 10.1007/s10584-0130722-7.

Kathuroju N, White MA, Symanzik J, et al. (2007) On the use of the advanced very high resolution radiometer for development of prognostic land surface phenology models. Ecological Modelling 201(2): 144-156. DOI: 10.1016/j. ecolmodel.2006.09.011

Linderholm HW (2006) Growing season changes in the last century. Agricultural and Forest Meteorology 137(1-2): 1-14. DOI:10.1016/j.agrformet.2006.03.006

Linderholm HW, Walther A, Chen D (2008) Twentieth-century trends in the thermal growing season in the Greater Baltic Area. Climatic Change 87(3-4): 405-419. DOI: 10.1007/ s10584-007-9327-3

Liu XD, Chen BD (2000) Climatic warming in the Tibetan Plateau during recent decades. International Journal of Climatology 20(14): 1729-1742. DOI: 10.1002/1097-0088 (20001130)20:14<1729:aid-joc556>3.0.co;2-y

Maisongrande P, Duchemin B, Dedieu G (2004) VEGETATION/SPOT: an operational mission for the Earth monitoring; presentation of new standard products. International Journal of Remote Sensing 25(1): 9-14. DOI: 10.1080/0143116031000115265

Memmott J, Craze PG, Waser NM, et al. (2007) Global warming and the disruption of plant-pollinator interactions. Ecology Letters 10(8): 710-717. DOI: 10.1111/j.1461-0248.2007.01061.x

Meroni M, Verstraete MM, Rembold F, et al. (2014) A phenology-based method to derive biomass production anomalies for food security monitoring in the Horn of Africa. International Journal of Remote Sensing 35(7): 2472-2492. DOI: $10.1080 / 01431161.2014 .883090$

Myneni RB, Keeling CD, Tucker CJ, et al. (1997) Increased plant growth in the northern high latitudes from 1981 to 1991. Nature 386(6626): 698-702. DOI: 10.1038/386698ao

Parmesan C, Yohe G (2003) A globally coherent fingerprint of climate change impacts across natural systems. Nature 421(6918): 37-42. DOI: $10.1038 /$ natureo1286

Penuelas J, Filella I, Zhang XY, et al. (2004) Complex spatiotemporal phenological shifts as a response to rainfall changes. New Phytologist 161(3): 837-846. DOI: 10.1111/ j.1469-8137.2004.01003.x

Penuelas J, Rutishauser T, Filella I (2009) Phenology feedbacks on climate change. Science 324(5929): 887-888. DOI: 10.1126/science.1173004

Piao SL, Cui MD, Chen AP, et al. (2011) Altitude and temperature dependence of change in the spring vegetation green-up date from 1982 to 2006 in the Qinghai-Xizang Plateau. Agricultural and Forest Meteorology 151(12): 15991608. DOI: 10.1016/j.agrformet.2011.06.016

Piao SL, Fang JY, He JS (2006a) Variations in vegetation net primary production in the Qinghai-Xizang Plateau, China, from 1982 to 1999 . Climatic Change 74(1-3): 253-267. DOI: 10.1007/s10584-005-6339-8 
Piao SL, Fang JY, Zhou LM, et al. (2006b) Variations in satellite-derived phenology in China's temperate vegetation. Global Change Biology 12(4): 672-685. DOI: 10.1111/j.13652486.2006.01123.x

Piao SL, Tan JG, Chen AP,et al. (2015) Leaf onset in the northern hemisphere triggered by daytime temperature. Nature Communications 6. DOI: 10.1038/ncomms7911.

Rembold F, Atzberger C, Savin I, et al. (2013) Using Low Resolution Satellite Imagery for Yield Prediction and Yield Anomaly Detection. Remote Sensing 5(4): 1704-1733. DOI: $10.3390 / \mathrm{rs} 5041704$

Robeson SM (2002) Increasing growing-season length in Illinois during the 2oth century. Climatic Change 52(1-2): 219-238. DOI: 10.1023/a:1013088011223

Rosenzweig C, Karoly D, Vicarelli M, et al. (2008) Attributing physical and biological impacts to anthropogenic climate change. Nature 453(7193): 353-357. DOI: 10.1038/ natureo6937

Schwartz MD, Hanes JM (2010) Intercomparing multiple measures of the onset of spring in eastern North America. International Journal of Climatology 30(11): 1614-1626. DOI: 10.1002/joc. 2008

Seghieri J, Vescovo A, Padel K, et al. (2009) Relationships between climate, soil moisture and phenology of the woody cover in two sites located along the West African latitudinal gradient. Journal of Hydrology 375(1-2): 78-89. DOI: 10.1016/j.jhydrol.2009.01.023

Shen MG (2011) Spring phenology was not consistently related to winter warming on the Tibetan Plateau. Proceedings of the National Academy of Sciences of the United States of America 108(19): E91-E92. DOI: 10.1073/pnas.1018390108

Shen MG, Sun ZZ, Wang SP, et al. (2013) No evidence of continuously advanced green-up dates in the Tibetan Plateau over the last decade. Proceedings of the National Academy of Sciences of the United States of America 110(26): E2329E2329. DOI: $10.1073 /$ pnas.1304625110

Shen MG, Tang YH, Chen J, et al. (2011) Influences of temperature and precipitation before the growing season on spring phenology in grasslands of the central and eastern Qinghai-Tibetan Plateau. Agricultural and Forest Meteorology 151(12): 1711-1722. DOI: 10.1016/j.agrformet.2011.07.003

Sherry RA, Zhou XH, Gu SL, et al. (2007) Divergence of reproductive phenology under climate warming. Proceedings of the National Academy of Sciences of the United States of America 104(1): 198-202. DOI: $10.1073 /$ pnas.0605642104

Song CQ, You SC, Ke LH, et al. (2011) Spatio-temporal variation of vegetation phenology in the Northern Tibetan Plateau as detected by MODIS remote sensing. Chinese Journal of Plant Ecology 35(8): 853-863. (In Chinese)

Sun HL, Zheng D, Yao TD, et al. (2012) Protection and construction of the national ecological security shelter zone on Tibetan Plateau. Acta Geographica Sinica 67(1): 3-12. (In Chinese)

Tao J, Zhang Y, Zhu J, et al. (2013) Elevation-dependent temperature change in the Qinghai-Xizang Plateau grassland during the past decade. Theoretical and Applied Climatology
117(1): 61-71. DOI: 10.1007/s00704-013-0976-z

Tang YH, Wan SQ, He JS, et al. (2009) Foreword to the special issue: looking into the impacts of global warming from the roof of the world. Journal of Plant Ecology 2(4): 169-171. DOI: 10.1093/jpe/rtpo26

Walther A, Linderholm HW (2006) A comparison of growing season indices for the Greater Baltic Area. International Journal of Biometeorology 51(2): 107-118. DOI: 10.1007/ so0484-006-0048-5

Walther GR (2003) Plants in a warmer world. Perspectives in Plant Ecology Evolution and Systematics 6(3): 169-185. DOI: 10.1078/1433-8319-00076

White MA, de Beurs KM, Didan K, et al. (2009) Intercomparison, interpretation, and assessment of spring phenology in North America estimated from remote sensing for 1982-2006. Global Change Biology 15(10): 2335-2359. DOI: $10.1111 / \mathrm{j} .1365-2486.2009 .01910 . \mathrm{x}$

White MA, Running SW, Thornton PE (1999) The impact of growing-season length variability on carbon assimilation and evapotranspiration over 88 years in the eastern US deciduous forest. International Journal of Biometeorology 42: 139-145. DOI: $10.1007 /$ s004840050097

White MA, Thornton PE, Running SW (1997) A continental phenology model for monitoring vegetation responses to interannual climatic variability. Global Biogeochemical Cycles 11(2): 217-234. DOI: 10.1029/97gboo330

Yu HY, Luedeling E, Xu JC (2010) Winter and spring warming result in delayed spring phenology on the Tibetan Plateau. Proceedings of the National Academy of Sciences of the United States of America 107(51): 22151-22156. DOI: 10.1073/ pnas.1012490107

Zhang XY, Friedl MA, Schaaf CB (2009) Sensitivity of vegetation phenology detection to the temporal resolution of satellite data. International Journal of Remote Sensing 30(8): 2061-2074. DOI:10.1080/01431160802549237

Zhang XY, Friedl MA, Schaaf CB, et al. (2003) Monitoring vegetation phenology using MODIS. Remote Sensing of Environment 84(3): 471-475. DOI: 10.1016/soo34-4257(02) o0135-9

Zhang XY, Friedl MA, Schaaf CB, et al. (2005) Monitoring the response of vegetation phenology to precipitation in Africa by coupling MODIS and TRMM instruments. Journal of Geophysical Research-Atmospheres 110(D12): 10.1029/2004 jdo05263. DOI: 10.1029/2004jdo05263

Zhang YL, Li BY, Zheng D (2002) A discussion on the boundary and area of the Tibetan Plateau in China. Geographical Research 21(1): 1-8. (In Chinese)

Zhang GL, Zhang YJ, Dong JW (2013) Green-up dates in the Tibetan Plateau have continuously advanced from 1982 to 2011. Procee-dings of the National Academy of Sciences of the United States of America 110(11): 4309-4314. DOI: 10.1073/ pnas.1210423110.

Zhou HK, Yao BQ, Xu WX, et al. (2014) Field Evidence for Earlier Leaf-Out Dates in Alpine Grassland On the Eastern Tibetan Plateau From 1990 to 2006. Biology Letters. 10(201402918). DOI: 10.1098/rsbl.2014.0291 